\title{
PAYLOAD CONFIGURATIONS FOR EFFICIENT IMAGE ACQUISITION - INDIAN PERSPECTIVE
}

\author{
D.R.M. Samudraiah ${ }^{\mathrm{a}}$, Manish Saxena ${ }^{\mathrm{a}}$, Sandip Paul ${ }^{\mathrm{a}}$, P. Narayanababu ${ }^{\mathrm{a}}$, Saji Kuriakose ${ }^{\mathrm{a}}$, A.S. Kiran Kumar

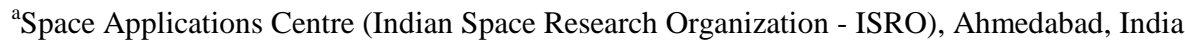 \\ drms@sac.isro.gov.in
}

\section{Commission VIII, WG VI/4}

\begin{abstract}
KEY WORDS: Remote sensing, image acquisition, resolution, electro-optical payload, data acquisition system, image acquisition efficiency
\end{abstract}

\begin{abstract}
:
The world is increasingly depending on remotely sensed data. The data is regularly used for monitoring the earth resources and also for solving problems of the world like disasters, climate degradation, etc. Remotely sensed data has changed our perspective of understanding of other planets. With innovative approaches in data utilization, the demands of remote sensing data are ever increasing. More and more research and developments are taken up for data utilization. The satellite resources are scarce and each launch costs heavily. Each launch is also associated with large effort for developing the hardware prior to launch. It is also associated with large number of software elements and mathematical algorithms post-launch. The proliferation of low-earth and geostationary satellites has led to increased scarcity in the available orbital slots for the newer satellites. Indian Space Research Organization has always tried to maximize the utility of satellites. Multiple sensors are flown on each satellite. In each of the satellites, sensors are designed to cater to various spectral bands/frequencies, spatial and temporal resolutions. Bhaskara-1, the first experimental satellite started with 2 bands in electro-optical spectrum and 3 bands in microwave spectrum. The recent Resourcesat- 2 incorporates very efficient image acquisition approach with multi-resolution (3 types of spatial resolution) multi-band (4 spectral bands) electro-optical sensors (LISS-4, LISS-3* and AWiFS). The system has been designed to provide data globally with various data reception stations and onboard data storage capabilities. Oceansat- 2 satellite has unique sensor combination with 8 band electro-optical high sensitive ocean colour monitor (catering to ocean and land) along with Ku band scatterometer to acquire information on ocean winds. INSAT3D launched recently provides high resolution 6 band image data in visible, short-wave, mid-wave and long-wave infrared spectrum. It also has 19 band sounder for providing vertical profile of water vapour, temperature, etc. The same system has data relay transponders for acquiring data from weather stations. The payload configurations have gone through significant changes over the years to increase data rate per kilogram of payload. Future Indian remote sensing systems are planned with very high efficient ways of image acquisition.
\end{abstract}

This paper analyses the strides taken by ISRO (Indian Space research Organisation) in achieving high efficiency in remote sensing image data acquisition. Parameters related to efficiency of image data acquisition are defined and a methodology is worked out to compute the same. Some of the Indian payloads are analysed with respect to some of the system/ subsystem parameters that decide the configuration of payload. Based on the analysis, possible configuration approaches that can provide high efficiency are identified. A case study is carried out with improved configuration and the results of efficiency improvements are reported. This methodology may be used for assessing other electro-optical payloads or missions and can be extended to other types of payloads and missions.

\section{INTRODUCTION}

The launch of Sputnik opened up opportunities for space exploration. The satellite technology has completely changed the communication scenario in the world. Remote Sensing (RS) satellites provide us unlimited access of image acquisition of land, oceans and atmosphere of the earth. The spacecraft observation facilitated planetary exploration in a great way. The launch of Landsat put the RS technology on a solid footing. Large number of quantitative studies and applications had been developed and operationalised. Considering the importance of RS technology, every country is trying to have its own RS system. Many countries have their own satellites. The first Indian experimental RS satellite was Bhaskar-1, an experimental satellite that was launched in 1979. Since then, ISRO designed, developed and operationalised a slew of RS satellites based on application requirements. It has launched 51 electro-optical instruments for earth and planetary studies.
There is a large amount of $R \& D$ concurrently progressing to develop new RS applications and accordingly, there is a demand for new satellites. Each satellite is associated with cost of development, launch and large number of ground support systems. It is a very complex activity to maintain, co-locate and coordinate many satellites in the orbits and their communication with the ground without interference from each other.

Today, satellites and their resources are premium. Presently there are about 3,500 functioning satellites (2) on orbit, of which $75 \%$ are junk. Out of operational satellites, half are in Low-Earth Orbit. More satellites are expected to be launched in future. Both Government and private Organizations from 41 countries will launch many satellites by 2023 . Based on published report (3), 1155 satellites (Earth observation and Communications) will be launched over the next decade (20142023). LEO Earth observation (EO) satellites will increase to 353 compared to 162 over 2004-2013. Both Government and 
private Organizations from 41 countries are expected to launch EO satellites by 2023. Considering the increase in satellites, decommissioned satellite decay time, space debris and space junk issues will increase and will call for regulations (Space law). Hence it is necessary to have efficient use of any satellite.

This paper attempts to develop an approach for analysing the image acquisition efficiency of RS payloads and satellites. As part of this, payload configurations of some of the Indian Remote sensing satellites which have electro-optical sensing instruments are analysed from the view point of data acquisition system and its efficiency. Section- 2 deals with methodology and data sources used and section-3 provides results and analyzes them and also suggests possible improvements for future with a case study. Section-4 summarises the studies.

\section{METHODOLOGY}

Payload defines the purpose of the satellite mission. Hence the efficiency of satellite largely depends on payload and its configuration. Electro-optical payload senses the light signal reflected/ emitted by object using various types of sensors, conditions the signal and digitizes it. Imaging system can be identified with parameters as given below-

- Geometric: Spatial resolution, swath, coverage (region/ country/ global- in how many days )

- Spectral: Bandwidth, no. of bands, coverage (which part of the spectrum- in how much time)

- Radiometric: Quantization, noise equivalent signal, Dynamic range (Minimum to Saturation - in how many gains/ exposures)

As can be seen from the above, payloads incorporate spatial, spectral, radiometric and time sampling of objects. Some of the payloads measure polarization also. They employ various scanning techniques like whisk-broom (pixel by pixel scanning), push-broom (line by line scanning), frame scanning etc. There are many papers that reviewed RS payloads with respect to RS parameters. There were no studies reported for evaluating the efficiency of Image acquisition system that can be used to assesses a system and compare its performance with others. The payloads are not standard data acquisition systems (DAS). But many similarities exist between RS payload and DAS. Like a data acquisition system, it has to sense light (sensors or pixels) through various spectral bands (channels) with certain ranges and resolutions at certain rates. The output of this function is the data and accordingly data rate (at generation stage) is taken as indication of performance of the imaging system as data acquisition system. Data rate (DR) can be defined as

$$
\mathrm{DR}=\left(\mathrm{N}_{\mathrm{s}} * \mathrm{~N}_{\mathrm{D}} * \mathrm{~N}_{\mathrm{DS}} * \mathrm{O}_{\mathrm{s}} * \mathrm{Q} * \alpha\right) /\left(\mathrm{T}_{\mathrm{S}} * \mathrm{~B}\right)
$$

$$
\begin{array}{ll}
\text { where } & \\
\mathrm{N}_{\mathrm{S}} & =\text { No. of spectral bands } \\
\mathrm{N}_{\mathrm{D}} & =\text { No of pixels per detection device } \\
\mathrm{N}_{\mathrm{DS}} & =\text { No. of detection devices per band } \\
\mathrm{O}_{\mathrm{S}} & =\text { Oversampling factor } \\
\mathrm{Q} & =\text { Quantization (bits per pixel) } \\
\mathrm{A} & =\text { Scan efficiency } \\
\mathrm{T}_{\mathrm{S}} & =\text { Exposure time + readout time } \\
\mathrm{B} & =\text { Binning (spatial or spectral) factor }
\end{array}
$$

We also define another parameter called spectral bits, which indicates the spectral, spatial and radiometric performance capability of the imaging system per square meter of ground projected pixel.

$$
\text { Spectral bits }\left(\mathrm{S}_{\mathrm{b}}\right)=\left(\mathrm{N}_{\mathrm{s}} * \mathrm{Q}\right) /(\mathrm{Ap})
$$

where

Ap $=$ Ground projected pixel area (in square meter).

Payload is generally designed to cater to functional, performance and reliability requirements. Each subsystem of the payload is designed and optimised for a mission using various concepts and technologies available with the designer at the time of design. Image acquisition schemes may be different but they all consume resources like mass and power. Considering the above, payload level Data acquisition efficiency is defined as below in few parameters.

Image acquisition Efficiency 1 (E-1)

$=\mathrm{DR} /$ Payload mass

Image acquisition Efficiency 2 (E-2)

$=\mathrm{DR} /$ Payload power

Image acquisition Efficiency 3 (E-3)

$=\mathrm{S}_{\mathrm{b}} /$ (Payload power/Instantaneous no. of pixels $)$

Image acquisition Efficiency 4 (E-4)

$=\mathrm{S}_{\mathrm{b}} /$ (Payload mass/Instantaneous no. of pixels)

DR is expressed as Kilo bits per second (Kbps), mass in $\mathrm{Kg}$ and power in Watts. Image acquisition efficiency at mission level depends on the spacecraft characteristics like altitude, power, mass, attitude accuracy, onboard storage memory, data compression capability, data transmission rate, maximum time for which the payload can be powered on, data transmission time and the ground data reception and processing facilities. Data volume is considered as an indicator of this performance.

$$
\mathrm{DV}=\mathrm{DR}_{\mathrm{t}} * \mathrm{C}_{\mathrm{f}} * \mathrm{~T}
$$

$\mathrm{DV}$ is the data volume in $\mathrm{MB}, \mathrm{DR}_{\mathrm{t}}$ is transmittable data rate (Mbps), $\mathrm{C}_{\mathrm{f}}$ is data compression ratio, if any and $\mathrm{T}$ is the minimum of Maximum time (in seconds) for which the payload could be powered on or the maximum time (in seconds) for which the transmission can be made in a day. Assuming that adequate number of ground stations are available for data reception, system level image/ data acquisition efficiency parameters are defined as below.

$$
\begin{gathered}
\text { System image acquisition efficiency (E-5) } \\
\text { = DV/ Spacecraft mass } \\
\text { System image acquisition efficiency (E-6) } \\
\text { = DV/ Spacecraft power }
\end{gathered}
$$

In the above definition of efficiency parameters, it is possible to combine the effects of mass and power. But, we have considered them separately to bring out corresponding optimisations that take place. Also, the mass and power data is available in system parameters.

Parameter data available from various Indian payload/ spacecraft documents is taken for this analysis and E-1 to E-6 are computed. Some of the payload parameters and subsystem parameters that affect the efficiency are also studied to bring out the major impacting factors. 


\section{RESULTS AND DISCUSSION}

Table-1 shows the Remote sensing satellite missions developed and launched by India with electro-optical payloads. Figures 1 to 5 show efficiency parameters E-1 to E-6 of some of these missions. It can be seen from Figures 1 to 5 that the efficiency parameters improved very significantly over the missions. E-1 increased from 9 to $100000 \mathrm{Kbps} / \mathrm{Kg}$ (four orders), E-2 from 18 to $53000 \mathrm{Kbps} / \mathrm{W}$ (> 3 orders), E-3 $<1$ to $96000 \mathrm{Spectral} \mathrm{bits/W}$ ( 5 orders), E-4 from $<1$ to 48000 spectral bits/Kg ( 5 orders) and E-5 increased to $4.3 \mathrm{~GB} / \mathrm{Kg} /$ day and E6 increased to $3 \mathrm{~GB} / \mathrm{W} /$ day. The reasons for the above are the improvements in spatial, spectral and radiometric resolutions while minimising the resource requirements. Figures- 6 and 7 show the mass and power of the payloads along with their data rates. It can be seen that while the data rates increased significantly, the resource requirements have increased very moderately. Figures 9 to 11 show the improvements in spatial, spectral and radiometric resolutions respectively. Figure- 8 shows the number of optical heads, sensor devices and electronic chains used for various payloads which indicate the design approaches to minimise the resources. There were many improvements that had taken place. In each of the new payloads, new concepts, components, materials, technologies are introduced and the developed approaches/ subsystems are carried forward to next payload with improvisation. Some of them are listed below.

- Adaptation of solid state devices

- Usage of push-broom scanning, step \& stare and TDI modes for image acquisitions

- Development \& deployment of multi-array (single package) and small pitch sense devices

- Design of miniaturised optics with associated demand on high frequency performance

- Design of compact optics to cater to wide wavelength range

- Incorporation of multiple bands/ spectrometers in minimum number of optical heads

- Usage of lightweight materials

- Integrated opto-mechanical design approaches for structural design and light weighting

- Usage of low power and high speed electronic components

- Usage of surface mounted devices \& high level of integration

- Qualification \& usage of off-the-shelf ICs \& components

- Usage of system on-chip cameras

Similar and significant improvements have taken place over the missions in spacecraft design and operations.

Table-1: Satellite missions developed and launched by ISRO with electro-optical payloads

\begin{tabular}{|r|l|l|l|l|}
\hline $\begin{array}{c}\text { SI } \\
\text { \# }\end{array}$ & Satellite & $\begin{array}{c}\text { Launch } \\
\text { year }\end{array}$ & Cameras & $\begin{array}{l}\text { Remar } \\
\text { ks }\end{array}$ \\
\hline 1 & Bhaskara-1 & 1979 & $\begin{array}{l}\text { Super } \\
\text { Vidicon } \\
\text { Cameras }\end{array}$ & $\begin{array}{l}\text { Earth } \\
\text { Observ } \\
\text { ation } \\
\text { EO) }\end{array}$ \\
\hline 2 & Bhaskara-2 & 1981 & $\begin{array}{l}\text { Super } \\
\text { Vidicon } \\
\text { Cameras }\end{array}$ & EO \\
\hline 3 & IRS-1A & 1988 & $\begin{array}{l}\text { LISS-1 \& } \\
\text { LISS-2 }\end{array}$ & EO \\
\hline 4 & IRS-1B & 1991 & $\begin{array}{l}\text { LISS-1 \& } \\
\text { LISS-2 }\end{array}$ & EO \\
\hline
\end{tabular}

\begin{tabular}{|c|c|c|c|c|}
\hline 5 & INSAT-2A & 1992 & VHRR & EO \\
\hline \multirow[t]{2}{*}{6} & INSAT-2B & 1993 & VHRR & EO \\
\hline & IRS-1E & 1993 & LISS-1 & EO \\
\hline 8 & IRS-P2 & 1994 & LISS-2 & EO \\
\hline 9 & IRS-1C & 1995 & $\begin{array}{l}\text { PAN, LISS- } \\
\text { 3, WiFS }\end{array}$ & EO \\
\hline 10 & IRS-P3 & 1996 & WiFS & EO \\
\hline 11 & IRS-1D & 1997 & $\begin{array}{l}\text { PAN, LISS- } \\
\text { 3, WiFS }\end{array}$ & $\mathrm{EO}$ \\
\hline 12 & INSAT-2E & 1999 & $\begin{array}{l}\text { VHRR, } \\
\text { CCD }\end{array}$ & EO \\
\hline 13 & Oceansat-1 & 1999 & OCM & EO \\
\hline 14 & TES & 2001 & PAN & EO \\
\hline 15 & Kalpana-1 & 2002 & VHRR & $\mathrm{EO}$ \\
\hline 16 & INSAT-3A & 2003 & VHRR,CCD & EO \\
\hline 17 & $\begin{array}{l}\text { Resourcesat- } \\
1\end{array}$ & 2003 & $\begin{array}{l}\text { LISS-4, } \\
\text { LISS-3*, } \\
\text { AWiFS }\end{array}$ & EO \\
\hline 18 & Cartosat-1 & 2005 & $\begin{array}{l}\text { PAN - } \\
\text { Stereo }\end{array}$ & $\mathrm{EO}$ \\
\hline 19 & Cartosat-2 & 2007 & PAN & EO \\
\hline 20 & Cartosat-2A & 2008 & PAN & $\mathrm{EO}$ \\
\hline 21 & IMS-1 & 2008 & Mx, HySI & $\overline{\mathrm{EO}}$ \\
\hline 22 & $\begin{array}{l}\text { Chandrayaan- } \\
1\end{array}$ & 2008 & TMC, HySI & $\begin{array}{l}\text { Moon } \\
\text { Observ } \\
\text { ation } \\
\end{array}$ \\
\hline 23 & Oceansat-2 & 2009 & OCM & EO \\
\hline 24 & Cartosat-2B & 2010 & PAN & $\mathrm{EO}$ \\
\hline 25 & Youthsat & 2011 & LiV-HySI & EO \\
\hline 26 & $\begin{array}{l}\text { Resourcesat- } \\
2\end{array}$ & 2011 & $\begin{array}{l}\text { LISS-4, } \\
\text { LISS-3*, } \\
\text { AWiFS }\end{array}$ & $\mathrm{EO}$ \\
\hline 27 & INSAT-3D & 2013 & $\begin{array}{l}\text { IMAGER, } \\
\text { SOUNDER }\end{array}$ & EO \\
\hline 28 & Mangalayaan & 2013 & $\begin{array}{l}\text { MCC, } \\
\text { MSM, TIS }\end{array}$ & $\begin{array}{l}\text { Mars } \\
\text { Obs. }\end{array}$ \\
\hline \multicolumn{5}{|c|}{ Planned } \\
\hline 29 & Cartosat-2C & 2015 & PAN, Mx & $\mathrm{EO}$ \\
\hline 30 & INSAT-3D-R & 2015 & $\begin{array}{l}\text { IMAGER, } \\
\text { SOUNDER }\end{array}$ & EO \\
\hline 31 & Cartosat-3 & $\begin{array}{c}2017 / 1 \\
8\end{array}$ & $\begin{array}{l}\text { PAN, Mx, } \\
\text { HySI }\end{array}$ & EO \\
\hline 32 & Oceansat-3 & 2017 & OCM, TIR & $\mathrm{EO}$ \\
\hline 33 & $\begin{array}{l}\text { Chandrayaan- } \\
2\end{array}$ & 2017 & $\begin{array}{l}\text { TMC-2, } \\
\text { IIRS }\end{array}$ & $\begin{array}{l}\text { Moon } \\
\text { Obs. }\end{array}$ \\
\hline 34 & HYSIS & 2018 & $\begin{array}{l}\text { HySI, VNIR } \\
\& \text { SWIR }\end{array}$ & $\mathrm{EO}$ \\
\hline
\end{tabular}




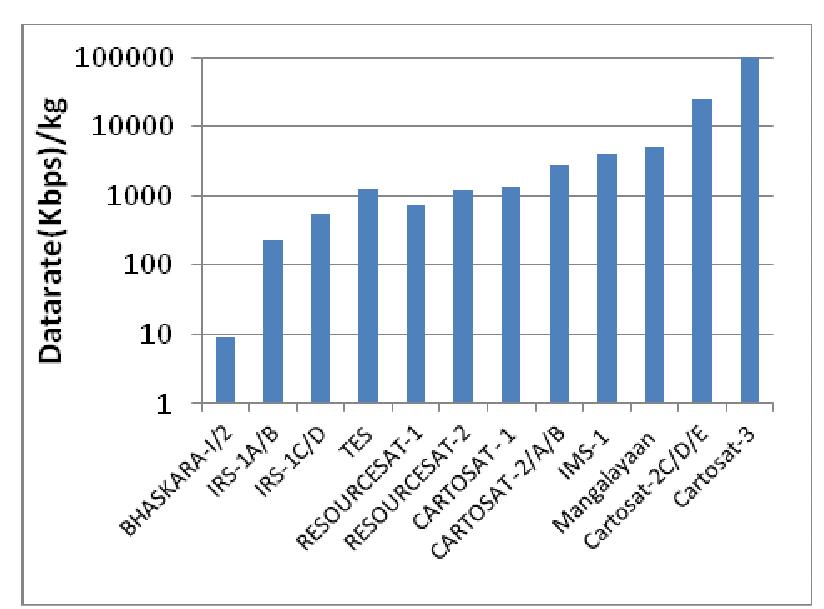

Figure-1: E1

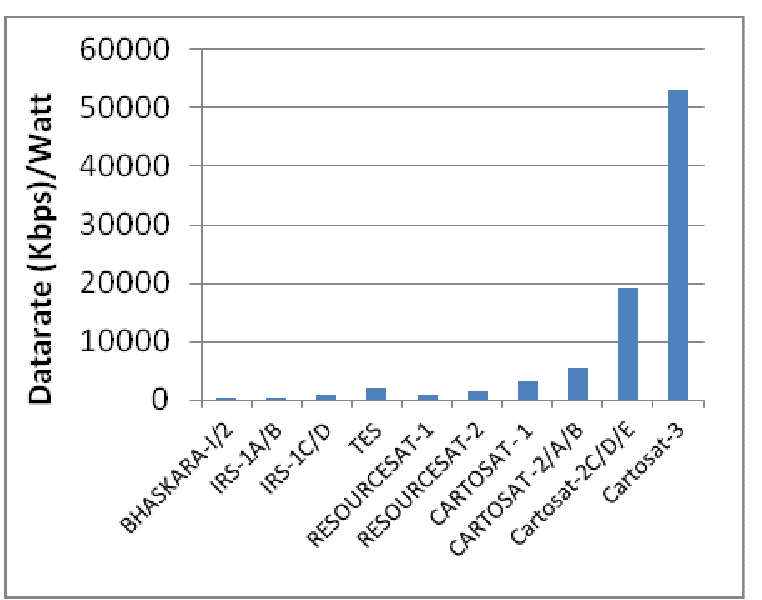

Figure-2: E2

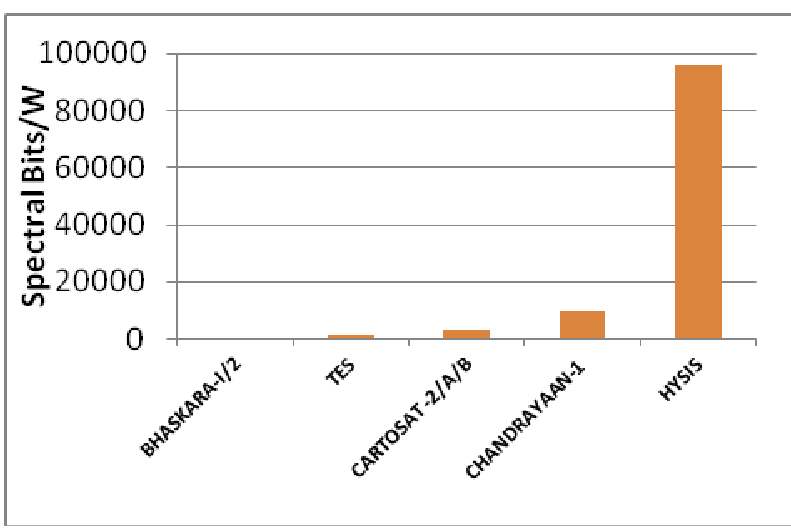

Figure-3: E3

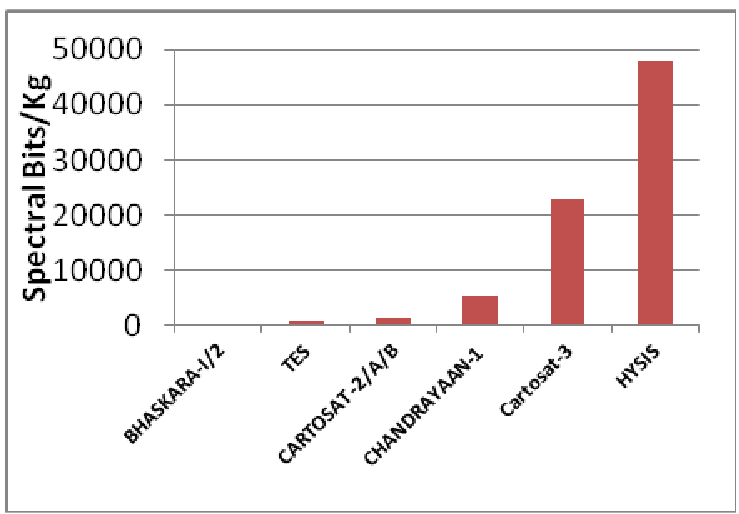

Figure-4: E4

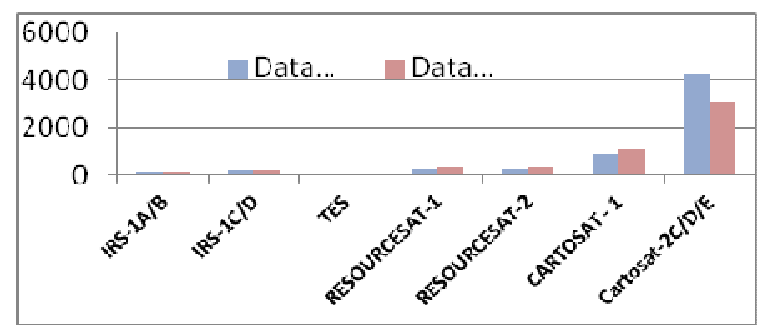

Figure-5: E5 and E6

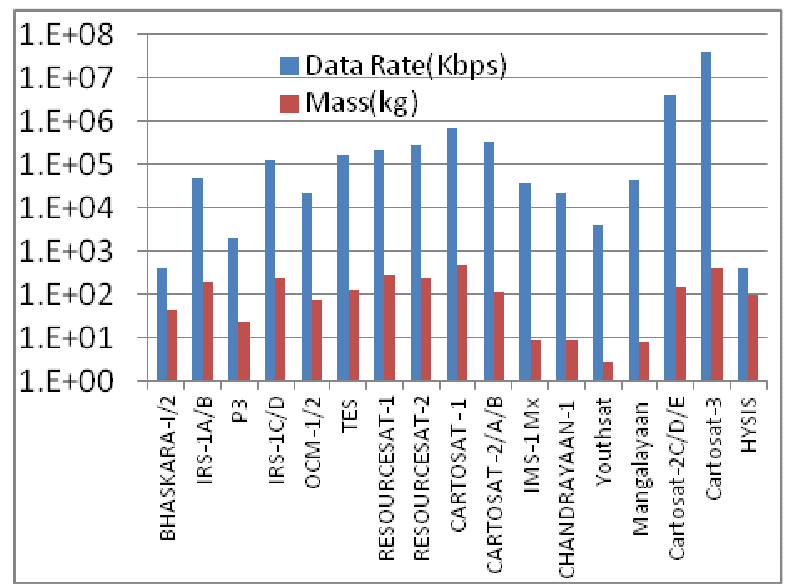

Figure-6

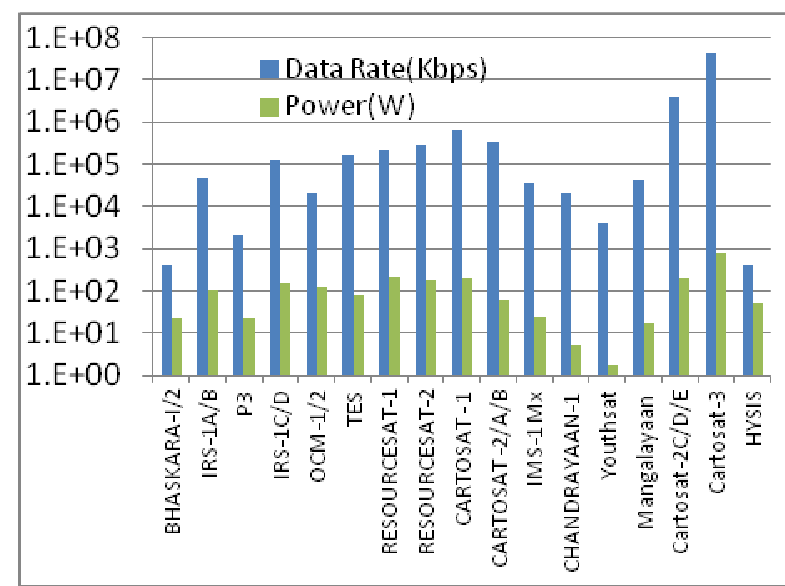

Figure-7 


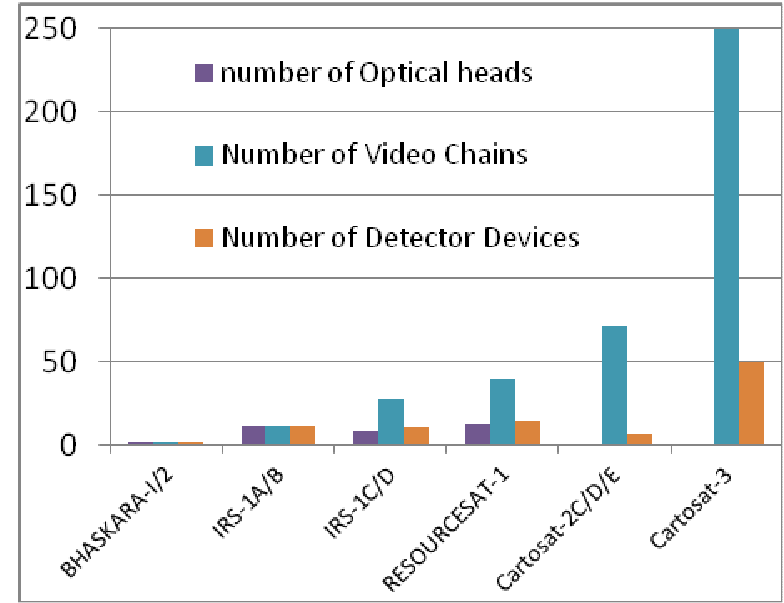

Figure-8

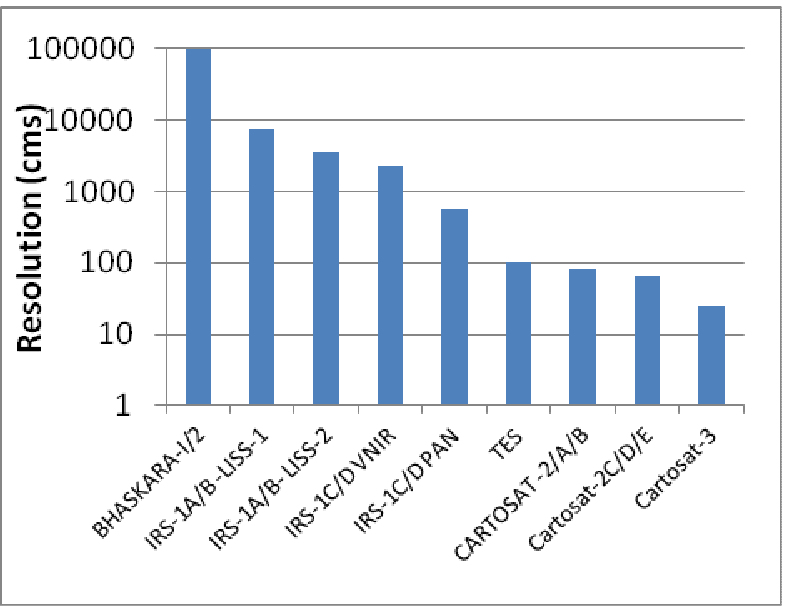

Figure-9

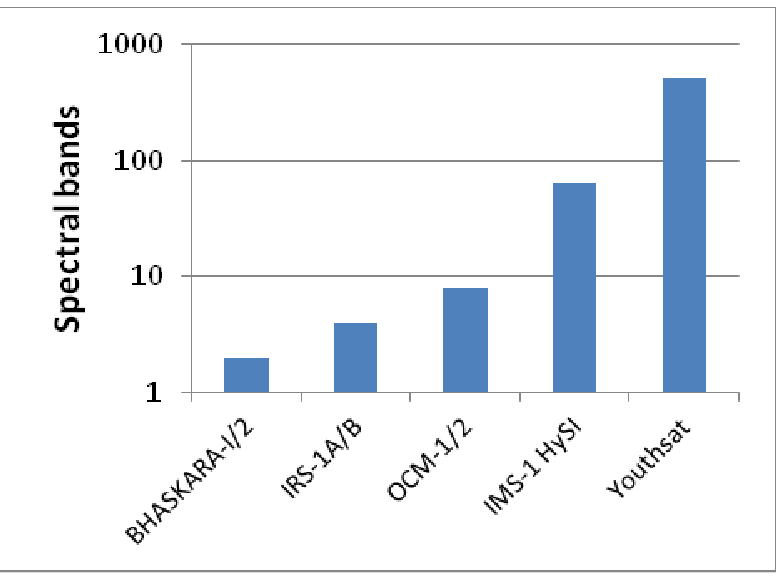

Figure-10

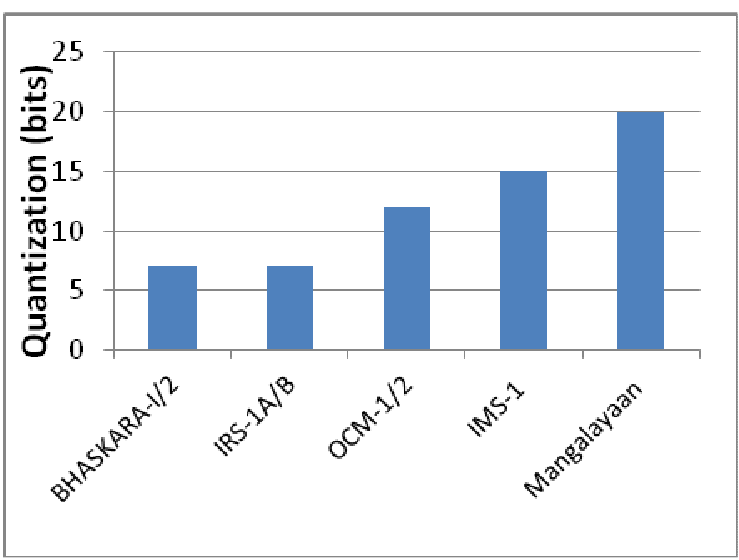

Figure: 11

Futuristic payload configuration- a case study:

It can be summarised from the above analysis following are the major reasons for improving the efficiency parameters.

(a) Large number of spectral channels in a single/ minimum number of optical heads

(b) High spatial, spectral and radiometric resolution systems

(c) Compact and light weight optics

(d) Low power and high speed electronics

Extending this further, a case study is carried out for future LISS-4 type sensors (LISS-4F). The sensor shall have (a) optical head catering to UV to LWIR spectral range (b) half of the image field catering to high spatial resolution multispectral (fixed bands in UV to LWIR) imaging (c) second half of the image field for medium/ coarse spatial resolution hyper spectral multispectral (UV to LWIR) (c) integrated hybrid electro optical devices for UV to LWIR and ROIC based architecture for Electronics. Tables-2 and 3 show the configuration and the efficiency parameters. Spatial and spectral requirements are based on assumed future RS requirements and what could be feasible from LISS-4 optics.

Table-2: Proposed payload parameters

\begin{tabular}{|l|c|c|c|c|c|c|c|c|}
\hline & \multicolumn{2}{|c|}{ UV-VNIR } & \multicolumn{2}{c|}{ SWIR } & \multicolumn{2}{c|}{ MWIR } & \multicolumn{2}{c|}{ LWIR } \\
\hline & L4 & $\begin{array}{c}\text { L4 } \\
\text { F }\end{array}$ & L4 & $\begin{array}{c}\text { L4 } \\
\text { F }\end{array}$ & L4 & $\begin{array}{c}\text { L4 } \\
\text { F }\end{array}$ & $\begin{array}{c}\text { L4 } \\
\text { F }\end{array}$ \\
\hline $\begin{array}{l}\text { Mx- } \\
\text { Resolution }\end{array}$ & 5.8 & 4 & - & 10 & - & 10 & - & 10 \\
\hline Mx- Bands & 3 & 6 & - & 2 & - & 2 & - & 6 \\
\hline $\begin{array}{l}\text { HySI } \\
\text { Resolution }\end{array}$ & - & 10 & - & 10 & - & 60 & - & 60 \\
\hline $\begin{array}{l}\text { HySI } \\
\text { Bands }\end{array}$ & - & 65 & - & 160 & - & 100 & - & 350 \\
\hline
\end{tabular}

Table-3: Efficiency parameters for proposed payload

\begin{tabular}{|l|c|c|}
\hline \multirow{2}{*}{ Parameter } & \multicolumn{2}{|c|}{ Value } \\
\cline { 2 - 3 } & LISS-4 & LISS-4F \\
\hline E-1 & 1500 & 280000 \\
\hline E-2 & 2230 & 75000 \\
\hline E-3 & 480 & 189000 \\
\hline E-4 & 327 & 70900 \\
\hline
\end{tabular}

The above system has very significant improvements in efficiency parameters. It may be noted that such system requires 
lot of developmental efforts in design and development of payload and satellite systems.

\section{CONCLUSIONS AND RECOMMENDATION}

In this paper, aspects related to efficiency of imaging system are discussed. The efficiency parameters relevant for data/ image acquisition are defined quantitatively and a methodology was evolved to arrive at these values for some of the Indian payloads and missions using system level parameters. An analysis of these parameters is also carried out using the payload's remote sensing parameters and configuration parameters. The analysis shows that the efficiency improves significantly over the missions due to maximisation of spectral channels in a given optical head, increase in spatial, spectral and radiometric resolutions, usage of compact, low mass and low power optical, electro-optical, mechanical and electronic systems. A case study was shown to further increase the efficiency parameters with LISS-4 optical head. The procedure outlines here for electro-optical payloads, can be extended for assessing the image acquisition efficiency of other types payloads/ missions and it may help in comparing various RS missions.

\section{ACKNOWLEDGEMENTS}

The analysis is primarily based on the evolution of electrooptical payloads at Sensors Development Area, Space Applications Centre, ISRO, Ahmedabad and authors profusely thank their present and past colleagues. We are grateful to other colleagues at other ISRO centres, whose work has been used for taking the system parameters. Special thanks to $\mathrm{Mr} \mathrm{M}$. Pitchaimani, Dy Director at ISTRAC, Mr Sadananda Rao, PD, Cartosat-2C, ISAC and Mr P. Murugan, IRS-PMO, ISAC for useful discussions and for providing some of the information. We sincerely thank Director, SAC for allowing us to carry out this research and publication.

\section{REFERENCES}

Various payload \& spacecraft documentation of ISRO

Centre for Space Standards and Innovation, NASA web site

Satellite-Based Earth Observation: Market Prospects to 2023, Euro consult's Report

Revised November 2014 